University of Nebraska - Lincoln

DigitalCommons@University of Nebraska - Lincoln

To Improve the Academy

Professional and Organizational Development Network in Higher Education

1994

Unconscious Values Within Four Academic Cultures: An Address

Given At The 1994 POD Annual Conference

William Bergquist

Follow this and additional works at: https://digitalcommons.unl.edu/podimproveacad

Part of the Higher Education Administration Commons

Bergquist, William, "Unconscious Values Within Four Academic Cultures: An Address Given At The 1994 POD Annual Conference" (1994). To Improve the Academy. 302.

https://digitalcommons.unl.edu/podimproveacad/302

This Article is brought to you for free and open access by the Professional and Organizational Development Network in Higher Education at DigitalCommons@University of Nebraska - Lincoln. It has been accepted for inclusion in To Improve the Academy by an authorized administrator of DigitalCommons@University of Nebraska - Lincoln. 


\section{Unconscious Values Within Four Academic Cultures:}

\section{An Address Given At The}

1994 POD Annual Conference

\section{William Bergquist}

It's wonderful being back to POD after an eight year hiatus. The POD Program Committee wheeled me out at the 10th anniversary of POD in 1986 to see if I was still alive. It was a real thrill for me at that meeting, for I had the opportunity to become reacquainted with old friends and new people. When I arrived at Lake Delavan (the site of the conference), I realized that as a child, I spent many wonderful weekends on this lake. As a result, I was often distracted during this conference. I kept reliving my childhood memories at Lake Delavan as well as my early years in the field of faculty and professional development. Rochester Minnesota is brand new for me, so if I'm not very coherent today, I have no recourse to childhood nostalgia though as a child I did spend many summers at one of the many lakes in Northern Minnesota. I don't think Rochester is close enough, however, to use this as an excuse!

\section{The Origins Of POD}

It is indeed exciting to be speaking at POD - for after 18 years I still take great pleasure in witnessing the exceptional progress of this organization. I was asked to say a few brief word about the founding 
of POD, having been present at its inception as an idea and later as it became a reality. POD was conceived in an office in Washington, D.C. by three people - two of whom you may not have even heard of: Gary Quehl and Dyke Vermillye. I was fortunate to be the third party at this meeting. I want to identify Gary and Dyke because they would be very pleased with this turnout today. Both of these men were extraordinary, visionary leaders in American higher education during the 1970s. At the time Dyke was President of the American Association for Higher Education and Gary was serving as President of the Council for the Advancement of Small Colleges (later renamed the Council of Independent Colleges).

These two men listened to a brash young educator (myself) talk about the new field called Faculty Development. Both Quehl and Vermillye had already sponsored specific faculty development programs, so I had no problem convincing them that this was an important new venture in American higher education. I suggested that they convene a national conference on this topic. They both agreed, and a meeting was planned for several months later at a lovely conference center called Wingspread (a Frank Lloyd Wright-designed home in Racine Wisconsin, that was originally built by the Johnson family of wax fame, who later turned it into a conference center).

Probably the critical decision made early on in planning for that conference concerned who would be invited. One of the people we talked about generated a fair amount of debate. We weren't sure whether to invite Bob Diamond from Syracuse University (a leading spokesperson for the field of instructional development) since, strictly speaking, he wasn't doing "faculty development." We weren't sure if we should bring Faculty and Instructional Development together. Thank goodness we did. Bob Diamond is here today and has played an important role in ensuring that these two fields interact.

At a second planning meeting another person was invited: Jack Lindquist. Jack is the one who added the "O" to POD. Jack said that the Wingspread Conference should consider not just faculty and instructional development, but also organization development. I want to acknowledge Jack Lindquist and his extraordinary contributions to this national association and to the field of organization development in higher education. He died much too early in life and his absence at 
this meeting is a painful reminder of just how important he was as a colleague and friend for many of us.

The notion of starting a national association was offered by many participants at the Wingspread Conference. By the end of the third and last day of that conference, considerable attention was given to the formation of POD. I'm very pleased to see that this national association has continued under the leadership of many different men and women. I look at the list of executive directors of POD and find the names of some people who were in attendance at Wingspread. However, many of the directors have joined POD since these founding years. Just for the record, by the way, you should know that the first Executive Director of POD was left off the list - that person being myself. I was executive director for approximately one hour. Every one (including myself) looked at me after my first hour of leadership and stated in unison that: "this man can't be our Executive Director." Fortunately, we picked Joan North instead. She became the first "real" Executive Director. I want it to be known, however, as a footnote to the history of POD, that there was someone else for one hour who served as executive director!

\section{The Unconscious Dimension Of Values In Academic Cultures}

On a more serious note, I was asked to talk with you today about a book I recently wrote called "The Four Cultures of The Academy." While I will summarize several of the conclusions I reached in writing this book, I want to move a bit beyond these conclusions, partly because some of you are already familiar with the book and several of you have heard me speak much too often on this topic. Partly, however, I want to move beyond the confines of the book in order to focus on two of the themes of this conference. First, I suspect that many of you are representative of one of the four cultures that I describe in the book. I call it the Developmental Culture. Development, after all, is what this organization is all about. I want to focus, therefore, on this culture.

Second, I was pleased to read about the emphasis on values at this conference. One of the areas I wanted to focus on, therefore, is what I call "the unconscious values" of the four cultures. I hesitate in using 
the term "unconscious." Because I am a psychologist, many of you may be assuming that I'm going to be talking about academic cultures in psychoanalytic terms - perhaps providing a Freudian analysis of bizarre happenings in American higher education. I want instead to use the term as Michael Polanyi (1967) might use it in reference to "tacit knowledge." Polanyi writes about our ability to recognize the faces of people we haven't seen for a long time and our ability to recognize that another person has changed his or her physical appearance, without being able to specify what this change is. We recognize other people, yet may not be able to remember their names or even when or where we have seen them before. We also can recognize that something has changed, but we don't know whether the person has lost or gained weight, changed their hair style or color, or gotten rid of (or grown) a beard.

Polanyi suggests we have a visual template that we apply in greeting a person. We match our "tacitly" (unconsciously) held template with this person's visual appearance and determine if we know this person: is there is a rough match between our template and this person's visual appearance? If there is a rough match, then we determine the extent to which this person still matches this template. For example, when my wife, Kathleen, comes home there will usually be an immediate and "unconscious" (or tacit) match between my template and her physical appearance. However, on occasion, there is not an immediate match and I tacitly know that something is different. Something has changed. I don't know whether she's excited or worried about something (which influences her facial expression) or if she has changed her hair style or worn a new dress or new piece of jewelry. I know something's different, but I don't know what it is. After a brief period of time, I can usually figure out what the mismatch is between my template and Kathleen's appearance. If I can't, then I must ask sheepishly what has changed.

Along with Michael Polanyi, I suggest that we tacitly hold many templates of the world in which we live and work. We continually match not only our facial templates, but also templates about leadership, communication, supervision, teaching and learning, and many other aspects of organizational life in our colleges and universities. We know when something is "right" or "wrong" in our college or 
university, even if we can't immediately identify what it is that is right or wrong. We also know that something has changed, even if we're not immediately quite sure what the change is or how we feel about this change.

I propose that when we examine organizational values, and more particularly values that reside within certain academic cultures, we are looking at "tacit knowledge." We know that these values are present and profoundly influence our life and our attitudes regarding the organization in which we work, yet these values are often not directly known to us. In other words, these values often remain "unconscious." They serve as tacitly-held templates against which we measure the "rightness" and "wrongness" of behaviors in our organization and the extent to which things have changed in our organization.

Obviously, some of our values inform our decisions in quite conscious ways. Chris Argyris and Don Schon (Argyris and Schon, 1974; Argyris, 1982) speak of these as our "espoused" values. We say that something is important to us and we act in a manner that demonstrates this importance. In other cases, however, our decisions and our actions may be dictated (or at least influenced) by values that we have not explicitly espoused. These values, at some deep level, influence how we act in our organization, even if we may not be able to identify these values and even if these values may contradict other values that we have consciously acknowledged and publically espoused. Furthermore, when the cultures that we live in begin to change, we know they have changed. We know that the values in our organization are changing, but we're not quite sure what it is that changed or why it has changed. This is at the heart of what I have identified as the "unconscious" dimension of values that are prominent in our four academic cultures.

\section{The Four Cultures Of The Academy: An Overview}

I will move to my analysis of the unconscious dimensions of academic values by first briefly describing the four cultures that I have identified in my book. In The Four Cultures of the Academy (1992) I propose that there are four prominent cultures in most American 
colleges and universities. I use the word "culture" with some hesitation - much as I use the word "unconscious" with some trepidation. I realize that my anthropology friends sometimes wince when I talk about "culture." I risk abusing a term that is central to their discipline. I hope I am using the term in an appropriate manner though I recognize that the differences between cultures in academic institutions is not even remotely as profound as the differences between ethnic cultures found throughout the world.

In essence, I suggest that there are two deeply rooted cultures in American higher education, which I have labeled "collegial" and "managerial." In addition, I have identified two more contemporary cultures that emerged in reaction to these two dominant cultures. I have labeled these the "negotiating" and "developmental" cultures. Let me briefly describe each of these four cultures.

\section{The Collegial Culture}

One of the two basic cultures, which I call the "Collegial Culture," is rooted in Colonial times. It is found at the very beginning of American higher education. As most of you are probably aware, the first colleges in America - such as Harvard and Yale - were based on what's called the Oxbridge model (a blending of Oxford and Cambridge). However, there was one aspect that was different from Oxford and Cambridge. Part of the reason that the colonial academics formed the first American colleges was because they had inadequate libraries. They wisely decided that they could improve their own personal libraries by combining them with the private libraries of other academically-inclined colonialists. In order to put their library into a single building, they had to pay rent on the space, as well as provide heat and things like that. So, they formed colleges in order to raise money for the building in which they placed their joint library. This, in turn, meant that these early academicians had to bring at least a few students in to pay the bills.

Obviously, there were other motivations. The early colleges served as training institutes for the clergy, physicians, and lawyers. They also served as "finishing schools" for the future (upper class) leaders of our society. Nevertheless, from the first, there was a sense 
in the collegial culture that colleges are really there for the faculty. Students were needed to pay the rent and keep the lights on, but they certainly weren't really there as welcomed guests.

The other important factor to consider in defining the nature of the collegial culture is that there were elementary schools, but no high schools in the original colonial period in the United States. After elementary school, young people were expected to go out and get a job or at least help out in the family business. A few of the young men (and later young women) did come back for a college education. The young men became ministers, physicians, or lawyers. The young women became polished hostesses for their elite husbands. These were the people who went on to college. At a later time high schools were formed to serve primarily in the early years as preparatory schools for those who were going on to college.Thus, from the first, American colleges were formed independently of the elementary schools and prior to the high schools. We still have that gulf today in the difficult articulation between high school and college. In many ways it's a remnant from the colonial years.

By the middle of the nineteenth century there was a major expansion in American higher education that came with the Federal Land Grant act. Many of the major universities in the United States were formed through these land grants, which provided not only space for the new campuses but also revenues (through sale of some of the deeded land). At the time these universities were formed, the German research university was considered the epitome of quality in the field of higher education. Oxford and Cambridge were no longer considered the premier institutions - for the physical sciences and research (the heart of the German university) had taken over from the humanities (which were at the heart of the Oxbridge model).

Thus, in the middle of the nineteenth century many leaders and professors were brought over to the United States as consultants or as the founders of academic departments in the new universities. These German academicians came over to help create the new institutions and in doing so they helped to form the character of the American University. The German Research University was quite different in many ways from Oxford and Cambridge. 
In the United States the Oxbridge and German subcultures merged. However, as in the case of the multiple dimensions of the other three cultures, several major contradictions exist between the Oxbridge and German models. Even in the 1990s, these two dimensions are not fully integrated in a single, coherent culture. Let me offer just one example of the inherent contradiction between these two subcultures. In the old Oxford-Cambridge model, science was at the bottom of the pecking order. The first science courses were not taught in America until the early years of the nineteenth century - and they were taught at West Point. Science courses were not taught in most colleges and universities because these disciplines were beneath the dignity of a "real" liberal arts college. There have obviously been some changes in terms of the status of sciences in our institutions. Today, the humanities often seem to be at the bottom of the pecking order. We can look to the impact of technology on our society as a partial reason for the radical change in the pecking order. However, the rise of the German research university model has also contributed to this change. Certainly the German Research University brought in a major infusion of support for the sciences. When I look at the Collegial Culture today, I think there is still tension between the Humanities and Liberal Arts (coming out of the Oxford-Cambridge model) and the Physical Sciences (coming out of the German Research University model). The fusion between these subcultures is still taking place.

\section{The Managerial Culture}

A second culture - that I have identified as "Managerial" — is quite different from the Collegial Culture. Like the Land Grant universities, the institutions from which this culture grew began in the middle of the nineteenth century. This culture came, not out of the Oxford-Cambridge model (which is primarily Protestant in origin), but, instead, out of the Catholic tradition in America. Many urban communities in the United States were just beginning to be established in the mid-nineteenth century. In many instances, these communities were composed primarily of recent immigrants from predominantly Catholic countries in Europe. The cathedral of the Catholic churches in these urban communities began providing a variety of services that 
were not yet being offered by public agencies (such as health care, child care, and education). It is very instructive to note how many human services in the United States were initially provided not by public institutions, but by the Catholic Church. Some of the first day care centers, schools, and human service centers came from the Catholic Church.

Initially, the Catholic Church provided elementary schools for its parishioners. As these children grew up, the church began to provide high schools, and eventually some of these children wanted a collegiate degree, so the Catholic Church began to provide college degree programs. In these Catholic colleges, leadership was provided not by the faculty or by professors-turned-academic-administrators (as in the case of the collegial culture), but rather by proven educational managers - typically men and women (in religious orders) who had already been successful high school administrators. The articulation between Catholic high schools and colleges was very effective, for they were all part of the same system in those days.

There was also a second component of the managerial culture: the junior and community college. As in the case of the Land Grant colleges and Catholic colleges, the junior colleges (later to become community colleges) were first formed in the second half of the nineteenth century in the United States. These colleges modeled themselves after neither Oxford-Cambridge nor the German Research University. Rather, they looked to the Catholic tradition of community-based service and the close articulation between high schools and colleges in the Catholic educational system. To this day we often find remnants of the old Catholic tradition in community colleges. For instance, there is a strong emphasis on hierarchy in what I call the Managerial Culture. Furthermore, both the Catholic institutions in the United States and community colleges display a strong emphasis on the examination of outcomes as well as a strong populist tradition.

The Collegial Culture has strong faculty emphasis while the Managerial Culture has generally a strong administrative bent. The primary career track toward academic leadership in the Collegial Culture is through faculty research and scholarship and through disciplinary affiliations. Conversely, academic leadership in the Managerial Culture comes primarily from faculty members moving up 
through departmental management to the positions of dean and vice president.

\section{The Negotiating Culture}

The third culture - what I have identified as "Negotiating" has emerged in reaction to the powerful managerial culture. During the last twenty years many faculty have concluded that if they are going to be treated as employees, then they need to respond as employees. In a collegiate institution that is dominated by the Managerial Culture, faculty began to seriously consider collective bargaining to insure that their personal and professional welfare is taken into account.

The Negotiating Culture, however, is built on more than just collective bargaining. As in the case of the Collegial and Managerial Cultures, the Negotiating Culture is composed of two subcultures that are sometimes in conflict. In addition to collective bargaining, the Negotiating Culture is built on the major movement in which many of us participated during the sixties and seventies and (in many instances) the eighties and nineties: the movement toward greater equity and social justice (civil rights, feminism, gay and lesbian rights, access for the disabled, and so forth). Many faculty have been deeply involved during the past twenty years in issues of access and equity and in the creation of programs for people who are not from Northern European/American origins, for women, for disabled people, and so forth. All of this is wrapped together in what I have called the Negotiating Culture.

In this culture, influence occurs not primarily through either research or scholarship (as is the case with the Collegial Culture) nor through management and budgets (as in the case of the Managerial Culture), but rather through collective action.

\section{The Developmental Culture}

Much as the Negotiating Culture came out of the Managerial Culture; the fourth culture - what I call the Developmental Culture - has roots in (and was founded in reaction to) the Collegial Culture. Those of us who live primarily in the Developmental Culture appre- 
ciate the collaboration of the Collegial Culture; we appreciate the norms around rationality and deliberation. We also appreciate the early emphasis in the Oxbridge model on the overall education of students - what the early Oxbridge professors spoke of as "forming the moral character" of its students. On the other hand, we don't appreciate the heavy political processes, the infighting and the indifference to student welfare that we often find in the German Research University and in the Collegial Culture that emerged from the attempted combination of the Oxbridge and German Research models. As a result, a new systematic emphasis was placed, during the 1960s and 1970s, on comprehensive student development. This new emphasis represents one of the two subcultures of the Developmental Culture. The other emerging emphasis concerns faculty, professional, and administrative development - which emerged as all of you know from the recognition during the 1960s and 1970s that our colleges and universities had to change if they were to accommodate the new students and the new challenges of American higher education. So, we begin to find in the early 1970s that unusual meetings were held in places like Washington D.C. and the Wingspread Conference Center, and organizations such as POD were formed as counter-weights to the dominant collegial and managerial cultures and as alternatives to the newly emerging negotiating culture.

While many of us from the first were comfortable with both the student development and faculty/professional development subcultures of the Developmental Culture, some tension still remains between these two different emphases. Which of the two emphases should be considered primary: do we begin with faculty development or student development? Should faculty development always be geared toward issues of teaching and learning? Do we justify administrative development because of its ultimate impact on students or because of its more immediate impact on the administrative operations of the school and the morale of administrators and staff who work inside the college or university? 


\section{Interaction Among the Four Cultures}

I propose that all four of these cultures exist in virtually every collegiate institution with which I have consulted and with every college, university, or graduate school of which I've been a member. Furthermore, I think it's essential, at least today, that all four of these cultures exist in every institution. When I look at institutions that are seriously in trouble, typically they're in trouble because they have successfully wiped out one of these cultures. Each of these cultures provides a valuable role in our contemporary colleges and universities and must be preserved.

\section{Developmental Culture In Dialogue With The Other Three Cultures}

I want to focus briefly on the strengths and weaknesses inherent in each culture. I will look at these factors from the perspective of the Developmental Culture and focus on the ways in which we, in the developmental culture, can best appreciate as well as challenge values that are embedded in those cultures that we are likely to perceive as alien or even antagonistic to our own cultural preferences.

\section{The Collegial Culture}

As a representative of the Developmental Culture, I greatly appreciate the broad-based participation that the Collegial Culture encourages. I have found it a bit ironic that corporate leaders come into our colleges and universities, preaching about "brand new" strategies such as the notion of self-managed work teams, broad participation in Total Quality Management, and Continuous Improvement programs. I often feel like saying, "Folks, we've been doing that in higher education for many years - if anything we often have too much participation in our planning and problem-solving processes." The presidents and deans of our collegiate institutions often say (with considerable justification): "No. No. We've got enough participation. Go away. We don't need the encouragement of more participation. Broad-based participation is part of our problem, not the solution." 
I firmly believe that the Collegial Culture has made American Higher Education an extraordinary and important part of our society, in large part because of this emphasis on broad-based participation. However, I wish the Collegial Culture were a bit more orderly - not quite so messy. I wish it wasn't so political. When Woodrow Wilson became President of the United States some people wondered whether his previous role as President of Princeton University was relevant to running affairs of state. Wilson was reported to have said something like: "After dealing with the politics of Princeton, I was surrounded by rank amateurs in Washington." The politics of our institutions are remarkably convoluted and complex. I want to say to my colleagues in the Collegial Culture: don't be quite as political and, most importantly, be more inclusive.

The important message for Total Quality Management, when it's working well in higher ed, is that the institution needs much broader participation in the decision making process. It helps break down the boundaries between faculty and staff, between faculty and administration. I think one of the major problems we now have, for those of us in our fifties and beyond, is to let loose of some of our control. In many instances, younger faculty members in our institutions have had to wait five or more years before they have much influence. Frankly, many are waiting for us to retire or die just so they can take over. I would suggest an alternative for those of us who are older and deeply entrenched in the collegial culture is to hand over some of our power and influence to the next generation of faculty in our institution.

A book that I recently coauthored on men and women in their fifties (Bergquist, Greenberg, and Klaum, 1993) suggests that the role of generativity is particularly important for those of us who have entered this decade of life. In our fifties, we are particularly inclined to be teachers or mentors (unless, as college teachers, we have already burned out on this role). We can move toward generativity by shifting out of positions of power in the collegial culture and moving into roles of facilitation, advisement, and wise counsellor. Such a shift is important for younger faculty as well as for our own psychological well-being. 


\section{The Managerial Culture}

To my colleagues in the Managerial Culture, I say I appreciate your orderliness - especially compared to the Collegial Culture. I appreciate your use of data. In our classrooms we're always espousing the importance of information and data. Yet, we know that faculty tend to be highly intuitive (as measured by the Myers-Briggs Type Indicator) and score very low on the sensing end of the Myers-Briggs scale. As faculty we tend to encourage our students to "pay attention to the data!" We inquire, "Did you do your reading? Do you have any facts to support that?" The intuitive faculty replies, "No! We haven't done a study, but we know it." I think it's useful that our colleagues in the Managerial Culture force us to gather some data.

One of the critical roles played by Bob Diamond and his colleagues in the Instructional Development field is that they serve as an effective bridge between the Managerial and Developmental cultures. Instructional development - like most of the other components of the managerial culture - is very student-oriented. It is very compatible with the student development subculture of the Development Culture (which came out of the student-oriented dimensions of the Oxbridge subculture). Because the subculture of faculty development originally came out of the faculty-oriented dimensions of Oxbridge and the German Research University subculture, its original advocates were often much too introspective and faculty-oriented. Ultimately, the student often got lost in many of our early faculty development efforts. For instance, many of my faculty development colleagues and I used to get very angry at the people at FIPSE (the Fund for the Improvement of Postsecondary Education - a federal funding agency) because, whenever we'd submit proposals for faculty development, they said, "What difference is this going to make in the life of students?" My colleagues and I would reply: "I don't know. It's for faculty!" They kept saying, "Your proposed program must have some impact on the students." The student orientation of FIPSE comes out of the Managerial Culture, and this orientation is to be commended - despite the objections of my faculty development colleagues and me.

Conversely, the Managerial Culture needs to be less rigid and less outcomes-oriented. One of the problems of the Managerial Culture is 
that it defines quality primarily in terms of outcomes and not enough in terms of process. I think members of the managerial culture need to be more collaborative. Total quality management does have several important messages for the Managerial Cultures within our colleges and universities, and most of these messages have to do with being more collaborative.

\section{The Negotiating Culture}

There's an interesting relationship between the Developmental Culture and the Negotiating Culture. One of the most intriguing questions for collective bargaining units, for instance, is: "As members of a faculty union, are we supposed to be in favor of faculty development, or against it?" A fair number of faculty unions in the United States are fully supportive of faculty development. They consider it part of their prerogative. On the other hand, many other faculty unions are opposed to faculty development because they consider it a slap in the face - another instance of their administration insensitively pushing programs down their throat or the administration saying that "you (the faculty) must improve" (rather than concluding that everyone must improve).

It is essential that more dialogue take place between the various faculty unions and organizations like POD. What would happen if POD were to cohost a conference with one of the major faculty unions? I want to say to my colleagues in the Negotiating Culture that I greatly appreciate your concern for equity. I think that's critical at this point in the history of American higher education. For those of us involved in professional, faculty, and instructional development, there is a provocative essay that was written many years ago by Goffman (1952) called "On Cooling the Mark Out." Goffman was studying carnivals and the way that those working in the carnivals manage the "marks" (customers like you and me). As the "marks" at a carnival, we spend money by participating in games such as throwing baseballs at six or more milk bottles that are stacked up at the other end of the booth. We throw baseballs at the milk bottles and find that they bounce off the bottles. At some point we realize that the bottles aren't just standing there; they're nailed down or hinged to the table! Someone probably 
has a lever, and he decides when they topple. We begin to get angry. Then someone comes up beside us, buys several tickets, and starts throwing balls at the milk bottles. This person also is not very successful. Finally, they speak to us, saying something like "This is crazy. Why don't we go off and have a beer or something together. Hey, I'll buy." They put their arm around us and off we go. We don't realize that these people are hired by the carnival. Their job is to cool off the mark. That is, they have learned how to cool us off when we get angry, so that we won't report the carnival to the local police.

One of the things we need to recognize as - developmental specialists and consultants - is that we often may be hired to cool the mark. That is, in our work in faculty development, instructional development, or organizational development, we need to be very careful because often there are legitimate grievances and differences of opinion from which we can divert attention in an effort to win our colleagues over to a more optimistic developmental perspective. Our colleagues in the Negotiating Culture teach us that there are conflicts in the organization that are appropriate because they have to do with the misallocation of resources, equity, and the distribution of power. Sometimes, when we're most successful, we have gathered a group of people together, and they've started feeling a little better about each other. They're not complaining as much. We need to be careful that we're not simply cooling the mark so that legitimate reform doesn't take place. I think our colleagues in the Negotiating Culture who may anger or frustrate us often are the people that are calling us to task about this issue of "cooling the mark."

\section{Personal Values of the Four Cultures}

I would now like to identify and briefly discuss the personal values that seem to be inherent in, or are at least closely associated with, each of the four cultures. I will try to identify some of the deep, underlying, and often unconscious or tacitly-held values of each culture. I will then turn, in conclusion, to an examination of group-based values in each culture. 


\section{The Collegial Culture}

In terms of the basic values, I think the most important value associated with the Collegial Culture is autonomy. It is apparently very important to respond to the needs and interests of faculty in the Collegial Culture in terms of their need for autonomy. It's also important, however, to realize that in the Collegial Culture, autonomy can turn into indifference, particularly among faculty members in their late forties and fifties. As faculty members, we've often spent our entire professional lives looking for autonomy. Somehow, in our lateforties and into our fifties, we find that we've finally achieved that autonomy but now feel very vulnerable. We feel isolated from our colleagues.

As we grow older, we tend to experience a growing interest in community and connectedness to a larger society (though at the same time we may focus on a smaller group of friends, family members and colleagues) (Bergquist, Greenberg, and Klaum, 1993). Frequently, as faculty members, when a greater interest in community does emerge, we look for that community not inside our colleges and universities (which now in some sense seem alien), but outside the college. We look to our local church, our disciplinary association, or a local community volunteer agency for our sense of community and connection. Inside the college we often tend to feel indifferent. I think it's particularly interesting that one of the most respected contemporary counsellors in American Higher Education is Parker Palmer, who talks about the spiritual dimension and about community in higher education.

\section{The Managerial Culture}

In the Managerial Culture, the most important value has been advancement - moving up through the ranks. This is the classic managerial emphasis that we find in other sectors of American society. Unfortunately, this emphasis on advancement is often thwarted in the Managerial Culture because there's not much room for advancement in most colleges and universities. Upward mobility works in large corporations, but not in either small colleges or large universities. There's not much to be done. We've created a Managerial Culture in 
an institution that doesn't have much verticality. There's nowhere to go, so we hit the glass ceilings again and again in higher education.

Often we find men and women in the Managerial Culture who are in their early - or mid - forties. They've reached the top and there's nowhere else for them to go. I think a major challenge in higher education is to find an alternative to upward mobility. What about moving horizontally to other positions? What about new uses of sabbaticals for people in managerial positions? One of the finest university presidents I've ever worked with is Ernest Hartung, who was president at the University of Idaho when I was an Assistant Professor at this university. He took a sabbatical in the midst of his presidency. Hartung had been a biologist at the University of Rhode Island and decided (with his board) to take a year off in order to work for the state of Idaho on a major environmental project. He returned as the rejuvenated President of the University, having made a valuable contribution to the state in his report on the environment. We don't do enough with sabbaticals for people in leadership positions.

\section{The Negotiating Culture}

I think the primary value of the Negotiating Culture - and I mean it in a positive sense - is power. People need to have the appropriate amount of power within the institutions in which they work. The downside of that is often a form of nihilism, or a lose-lose kind of mentality: If I can't have the power, then no one will have the power. I fear that many times in the Negotiating Culture we break the backs of our collegiate institutions; we bring them to their knees in part because they don't listen to us.

Collaborations between the Developmental Culture and the $\mathrm{Ne}-$ gotiating Culture are very important. As developmental advocates, many of us tend to be idealists and optimists. By contrast, advocates of the Negotiating Culture often are very pessimistic, and in their pessimism, they often can be very destructive. The two cultures tend to balance off each other, so that faculty members are appropriately realistic without losing their idealism and their sense of potential improvement in their institution. 


\section{Group Values Of The Four Cultures}

In conclusion, I want to touch on a few of the values that exist at the group level in collegiate institutions.

\section{The Collegial Culture}

At the group level coherence is highly valued in the Collegial Culture. Faculty want to pull the political process together from out of chaos. There is a concept in chaos theory that I think is very appropriate as we look at the Collegial Culture - this is the notion of strange attractor. If we have a smooth surface with a very small dent, then dirt, water, or any other substance will tend to move toward that little dent. The dent gets deeper and deeper as these substances move into and out of the dent. Eventually the dent becomes a hole. Slight variation becomes a major variation. Small cracks become large potholes. Minor events eventually bring about profound change.

We have many strange attractors in the political processes of our colleges and universities. A small issue gradually begins to absorb all of the energy and attention of faculty in the institution. This issue soon distracts faculty from other more important matters. The political process becomes nothing more than an energy drain, a strange attractor. In his book on the dynamics of academic organizations, Birnbaum (1988) offers a very interesting change strategy called the "garbage can," which makes extensive use of the strange attractor phenomenon. In essence, if you want to change your institution, then bring some issue before the faculty that will absorb all of their attention - a nice meaty issue like parking or general education, an issue that has absolutely no resolution. You bring it before the faculty and the faculty will put all of their energy into this issue - many hours, many subcommittee hearings. While they're all working on this distracting issue - this strange attractor - you run around the edge of the issue and unilaterally initiate a project that you think is actually of some importance. No one on the faculty has the energy to move away from whatever the strange attractor (garbage can) issue is to address concerns associated with your pet project. I think that this is probably a very useful strategy, though perhaps a bit Machiavellian. 
A variant on the garbage can strategy was developed by some of the people involved in the free speech movement at Berkeley. We should listen carefully to the reflections of these young men and women (many of whom are ourselves!), for as students of the sixties, we often changed academic organizations much more easily than we've changed them in more recent years, as faculty and administrators. Several of the student activists of the 1960s and 1970s noted that most bureaucratic policies and procedures are set up to prevent you from doing something. However, if you do what you want to do without asking for bureaucratic permission, then those people who want to stop you from doing it have to go through these same mechanisms to stop you. Thus the bureaucratic mechanisms that were set up to prevent you from doing something in the first place suddenly become your allies or your shield. By the time the bureaucrats and opposition leaders finally move through all the red tape to get you to stop doing whatever you've been doing, you've already finished. Then you simple say, "I'm sorry" or even "I'll never do that again." Several corporate consultants (who were probably the somewhat more radicalized activists of the sixties when they were younger) have captured the essence of this approach when they suggest that it is much easier to beg for forgiveness than to ask permission.

My sense is that this type of political, manipulative process tends to be very alien and offensive to most of us in the Developmental Culture. These political intrigues often eventually prevent our institutions from making thoughtful and successful decisions, much as the strategies used by the negotiating culture can be very destructive when not tempered by the more thoughtful (though sometimes naive) deliberations of the developmental and managerial cultures. Thus, an emphasis is placed on coherence in the Collegial Culture because the manipulations that are possible in this culture can shatter the unity and ultimately the very fabric of institutional life in a college or university that is dominated by this culture.

\section{The Managerial Culture}

I propose that consensus is at the heart of the group-oriented values espoused in the Managerial Culture. I think it often gets 
overlooked by those of us who do not primarily dwell in this culture. Unfortunately, when you have a movement towards consensus, you often have the creation of artificial agreements. Some of you know of the so-called "Abilene Paradox" that works so profoundly in our institutions. This paradox occurs when everyone in a group agrees to a particular course of action, though none of the group members individually believe that this is the best course. All members of the group go along with the nonpreferred course of action because they erroneously believe that other members of the group all support this choice.

Recently, I was working with the library system in a Midwest university that exemplifies this paradox. The head of the library said, "Well, my problem is that every time I present a new idea my staff put it down."I asked him for an example of an idea that had been dismissed by his staff. He mentioned one idea that the staff had "really put down." Incidentally, during my interviews with each of his 14 subordinants, I asked: "What do you think of this idea?" Inevitably each of the staff members indicated that: "I think it's a good idea, but the other people on this staff think it's really lousy." At the end of a meeting, in which I summarized the results of my interviews, I said: "By the way, did you know that everyone in this room supports this idea?" They all looked around at each other. I said, "One of you expressed some concerns about the idea, but indicated that he wasn't opposed to this idea." In this group, there was such a strong assumption that this is a place where new ideas aren't accepted. No one spoke up because no one wanted to be the only one supporting the boss's ideas. This exemplifies the manufacturing of artificial consent, an Abilene Paradox.

I think members of the higher education community are particularly vulnerable to this paradox because we are fearful of being considered a fool or of being exposed. This is an area where I think we can be particularly helpful as organization development consultants. We can challenge the assumption that everyone is against an idea, or, conversely, that everyone's for the idea. 


\section{The Negotiating Culture}

I think the most important value in the Negotiating Culture is often one that is not clearly understood by many of us who are outside that culture. It is the notion of what I would call effective confrontation. Everyone must play their parts. I was reminded of this value in Erik Erikson's (1970) description of Gandhi's first strike in India. Gandhi's first nonviolent demonstration occurred in a mill that was run by a man with whom Gandhi had grown up. They had been close friends as children. The two men participate in the demonstrations each morning - each man leading the opposing parties - and in the late afternoon met with one another over a cup of tea to discuss the happenings of the morning. They went over the events of the day to insure that both parties were playing their proper roles. Both of these men felt that this was a drama that needed to be acted out. The only way it could be properly performed was if each party played his role in an effective manner. I see collective bargaining working in a constructive manner when each party truly respects the other party and realizes that these basic differences and conflicts are probably never going to be (and perhaps never should be) fully resolved - at least if it means that one of the parties will lose absolutely and the other will win absolutely. Both parties to this deliberation must be strong. The negotiating that occurs when one party is weak is not very effective negotiation. I think that we, in the Developmental Culture, have a lot to say about that. We have many suggestions to make regarding how one might help two parties come to the point where they can respect each other and still be in negotiation.

\section{The Developmental Culture}

I would like to conclude by speaking briefly about the group values in our own culture, the Developmental Culture. At the heart of our culture is the notion of collaboration. I met (at the POD Conference) with several colleagues last night who were talking about POD. They observed that people in this organization come together and share with one another. People in this organization seem to believe strongly in collaboration. Peter Senge (1990) has recently highlighted the distinction between discussion and dialogue. I think our Develop- 
mental Culture is in the business of dialogue. Discussion is a matter of clashing or percussion. Discussion is based on conflict and competition. In the case of dialogue, we begin by trying to discover that which we hold in common, that which underlies our relationship, that which brings us together. What is it that we share?

Once again, I refer to the essential collaboration between the Negotiating and Developmental Cultures. I think one's role in either the Negotiating or Developmental Culture is most effectively served when we bring people together. We should engage in dialogue rather than discussion, regardless of whether we are negotiating for equity and justice or planning for the growth and maturation of all members of a collegiate institution.

The negative side, I think, of our Developmental Culture is what I've already mentioned: "Cooling the Mark." We need to be very careful. How might we have worked with Gandhi, for instance, as an organization development consultant. One of us might sit down with Gandhi and his colleague in order to convince both of them that they really care about each other. Furthermore, if they really do care about each other, then they shouldn't go out every morning and confront one another in public. We might convince them both that this is a silly misunderstanding. If we had been successful, this important drama might never have taken place.

It's not our role as advocates of the Developmental Culture to try to diminish or subvert important and inevitably difficult discussions and deliberations regarding equity and social justice in our institutions. However, I do think we can help transform these discussions into dialogues. We can help both parties become more productive and can encourage both parties in that dialogue to listen to each other more effectively. Perhaps, as a first step, we can begin to practice what we preach by listening more carefully and attempting to understand and more fully appreciate the rich and complex values associated with each of the four cultures of our contemporary colleges and universities. I hope that my comments today have been of some worth in this regard. 


\section{References}

Argyris, C. (1982). Reasoning, learning and action. San Francisco: Jossey-Bass.

Argyris, C. and Schon, D. (1974). Theory in practice. San Francisco: Jossey-Bass.

Bergquist, W. (1992). The four cultures of the academy. San Francisco: Jossey-Bass.

Bergquist, W., Greenberg, E. and Klaum, A. (1993). In our fifties. San Francisco: JosseyBass.

Birnbaum, R. (1988). How colleges work. San Francisco: Jossey-Bass.

Erikson, E. (1970). Gandhi's truth. New York: Norton.

Goffman, E. (1952). On cooling the mark out, Psychiatry, 15, 451-463.

Polanyi, M. (1967). The tacit dimension. New York: Doubleday.

Senge, P. (1990). The fifth discipline. New York: Doubleday. 